\title{
Relationship between Learning Style and Academic Status of Babol Dental Students
}

\author{
Zahra Nasiri $^{1}$, Samane Gharekhani ${ }^{2}$, Maryam Ghasempour ${ }^{3}$
}

${ }^{1}$ Dental Student, Student's Research Committee, Faculty of Dentistry, Babol University of Medical Sciences, Babol, Iran

${ }^{2}$ DDS, Assistant Professor, Department of Pediatric Dentistry, Faculty of Dentistry, Babol University of Medical Sciences, Babol, Iran

${ }^{3}$ DDS, Associate Professor, Department of Pediatric Dentistry, Faculty of Dentistry, Babol University of Medical

Sciences, Babol, Iran

\section{Type of article: Original}

\begin{abstract}
Introduction: Identifying and employing students' learning styles could play an important role in selecting appropriate teaching methods in order to improve education. The aim of this study was to determine the relationship between the students' final exam scores and the learning style preferences of dental students at Babol University of Medical Sciences.

Methods: This cross-sectional study was conducted on 88 dental students studying in their fourth, fifth, and sixth years using the visual-aural-reading/writing-kinesthetic (VARK) learning styles' questionnaire. The data were analyzed with IBM SPSS, version 21, using the chi-squared test and the t-test.

Results: Of the 88 participants who responded to the questionnaire, 87 preferred multimodal learning styles. There was no significant difference between the mean of the final exam scores in students who did and did not prefer the aural learning style $(\mathrm{p}=0.86)$, the reading/writing learning style $(\mathrm{p}=0.20)$, and the kinesthetic learning style $(\mathrm{p}=0.32)$. In addition, there was no significant difference between the scores on the final clinical course among the students who had different preferences for learning style. However, there was a significant difference between the mean of the final exam scores in students with and without visual learning style preference $(\mathrm{p}=$ 0.03 ), with the former having higher mean scores. There was no significant relationship between preferred learning styles and gender $(\mathrm{p}>0.05)$.

Conclusion: The majority of dental students preferred multimodal learning styles, and there was a significant difference between the mean of the final exam scores for students with and without a preference for the visual learning style. In addition, there were no differences in the preferred learning styles between male and female students.
\end{abstract}

Keywords: Academic status, Dental students, Learning styles

\section{Introduction}

In the information age, the development of science and technology and the expansion of various sciences make it very important to gain more and consistent data in a short time (1). Learning clinical science is a challenge in the lives of the students of medical science, necessitating an applicable pluralization of the knowledge and skills that are acquired in a hospital setting. There are several factors that affect learning, one of which is learning style (2). In recent years, medical education trends have changed from teacher-centered and subject-based teaching to the use of interactive, problem-based, student-centered learning. Therefore, it is necessary for educators to recognize the different learning styles of students (2). Learning style is a habitual and unique behavior to acquire knowledge, skills, and feedback through study or experience; it is the way that learners prefer to over other ways in their content learning process, and it is the most efficient and effective learning method for every learner. Thus, every student has

\section{Corresponding author:}

Associate Professor Dr. Maryam Ghasempour. Department of Pediatric Dentistry, Faculty of Dentistry, Babol University of Medical Sciences, Babol, Iran. Tel: +98.1132291408, E-mail: Ma_ghasempour_ir@yahoo.com

Received: October 17, 2015, Accepted: January 07, 2016, Published: May 2016

iThenticate screening: December 12, 2015, English editing: February 23, 2016, Quality control: May 02, 2016

(C) 2016 The Authors. This is an open access article under the terms of the Creative Commons Attribution-NonCommercialNoDerivs License, which permits use and distribution in any medium, provided the original work is properly cited, the use is non-commercial and no modifications or adaptations are made. 
a personal style for receiving, processing, saving, and remembering new information $(3,4)$. Therefore, the learners' efficiency will be better if their learning process is matched with their learning style (5). Conversely, incompatibility between the teaching method and the person's learning style results in demotivation and failure in learning (6). If the medical students become aware of their learning styles, they can learn more information in a shorter time. According to Fleming's observations, being aware of learning styles helps students select the best method of receiving information and subsequently changing their methods of study (2). Many studies have shown that compatibility between teachers' teaching methods and students' learning styles leads to encouraging students to learn and better educational achievement. As a result, it is necessary that teachers be aware of students' learning styles and try to match their teaching and testing method with those learning styles $(4,7)$. There are several ways to recognize students' learning styles based on their different psychosomatic behaviors, which can be determined by using various tools, including questionnaires developed by Dunn, Kolb, Keefe, Gregorc, Felder Fleming, and Soloman. Felder Fleming introduced the Visual, Aural/Auditory, Reading-Writing and Kinesthetic (VARK) questionnaire to determine learning styles (4). The VARK learning styles questionnaire was developed at the Lincoln University of New Zealand in 1998. It is based on three principles: 1) Everyone can learn academic issues but has her or his own style; 2) The learners' motivation increases when their different learning styles are taken into account; and 3) Educational concepts are learned through utilization of senses and different perceptions (8). According to VARK's perspective, students acquire knowledge through four sensory channels based on interaction and response to their learning environment: 1) Visual: In this style people learn best by observation and visual presentation; 2) Aural or auditory: Learners learn best through listening and verbal instructions; 3) Reading-Writing: In this style people learn best by taking notes during reading written or printed texts and lectures; 4) Kinesthetic or practical: Learners learn best by carrying out physical activities $(8,9)$. There are some published data on learning styles among medical students, but few studies have investigated the relationship between learning styles and the mean of students' final exam scores. For example, a study conducted by Al-Saud (10) in Saudi Arabia on first-year dental students found that $59 \%$ of the students preferred multiple learning styles. In addition, there were no statistically significant differences between males' and females' preferences for learning styles. However, there was a statistically significant difference in the mean values of GPAs (grade point averages) in relation to the students' preferences for learning styles. The field of dentistry is combined of theoretical and practical courses; therefore, it is important to recognize students' learning style preferences in order to design an effective educational curriculum and provide learning opportunities. In Iran, although several studies utilizing the VARK questionnaire have been conducted among different fields of medical sciences $(5,8,11-13)$, few studies have been done to identify the learning preferences of dental students. This study was conducted to determine the relationship between the mean of final exam scores and learning style preferences of dental students at Babol University of Medical Sciences. In addition, this study explored the relationship between learning style preferences and students' gender and grades.

\section{Material and Methods}

\subsection{Setting and Participants}

This descriptive, analytical, cross-sectional study was performed with 88 dental students who were studying in their fourth, fifth, and sixth years at Babol University of Medical Sciences from August 2013 to February 2014. The study group was selected by census report. The criteria for participating in the study was the participants' willingness and consent.

\subsection{Instruments}

Data were collected using the VARK questionnaire, which consisted of two parts. The first part was related to demographic information, including questions on age, gender, and grade level. The second part was the VARK standard questionnaire version 7.0, which was used to determine the learning styles of the students. The VARK questionnaire was developed by Fleming at Lincoln University in New Zealand in 1998 (14). The VARK questionnaire consists of 16 multiple choice questions with four options. All the options corresponded to the four sensory modalities measured by VARK (visual, aural/auditory, read/write, and kinesthetic). This questionnaire has been used several times in Iran, and its Cronbach's alpha coefficient has been calculated $(\alpha=0.86)(5)$. In the present study, the questionnaire was administered by hard copy, although it also is available online. The questions were constructed based on the individuals' performance in different situations. According to the instructions, each participant could select one or more items. Definition of words used to describe various learning style preferences are:

1) Single modal: Having one of the $\mathrm{V}, \mathrm{A}, \mathrm{R}$ or $\mathrm{K}$ preference

2) Multimodal: Having more than one preference

3) Bimodal: Having two preferences 
4) Tri-modal: Having three preferences

5) Quad-modal: Having all of the four preferences (3)

\subsection{Research ethics and procedures}

Ethical approval for the study was obtained from the University's Research Ethics Committee at Babol University of Medical Sciences (Ref. no.: 5032). The researcher distributed the questionnaires to the participants in their classrooms and provided the information they needed to complete them. The students answered the questions, and the data were collected at the same time. After the students answered the questionnaires, the scores for every learning style were calculated based on the students' answers in order to determine the learning style preferences. In the next step, the total scores of the questionnaires were calculated by summing the scores of all of the questions. The total scores of the questionnaires were divided into four groups, i.e., questionnaires in which the total scores of students were 10-16, 17-22, 23-30, and $>30$. Those learning styles whose score was two or less were omitted when the total score of the students' questionnaires was in the 10-16 range; those learning styles whose score was three or less were omitted when the total score of the students' questionnaires was in the 17-22 range; those learning styles whose score was four or less were omitted when the total score of the students' questionnaires was in the 23-30 range; those learning styles whose score was five or less than five were omitted when the total score of the students' questionnaires was over 30. After omission of the learning styles whose scores were less than the minimum of each group, the remaining learning styles were the preferred learning styles for each individual. Students' academic status was measured by the mean of students' scores at the end of the semester.

\subsection{Statistical Analysis}

The data were analyzed by IBM SPSS, version 21. The number of students who preferred each mode of learning style was divided by the total number to calculate the percentage of students in each group. The chi-squared test was used to compare the differences in distributions of learning style preferences by gender and students' grade levels. The t-test was used to investigate the differences in the mean of students' final exam scores and their learning style preferences. A $p$-value of $p \leqslant 0.05$ was considered statistically significant.

\section{Results}

Of the 102 questionnaires that were distributed, 88 were completed and returned by the students. The other questionnaires were not returned because some of the students graduated or did not want to participate. Of the 88 participants 56 were females (63.6\%), and the others were males. Also, among the 88 participants, 18, 33, and 37 were studying in their sixth, fifth, and fourth years, respectively. The majority of the students (87 individuals) preferred multiple learning styles (multimodal), of which 18.1, 56.8, and 23.8\% were bi-modal, tri-modal, and quadmodal, respectively. Only one student had a single learning preference (aural) (Figure 1).

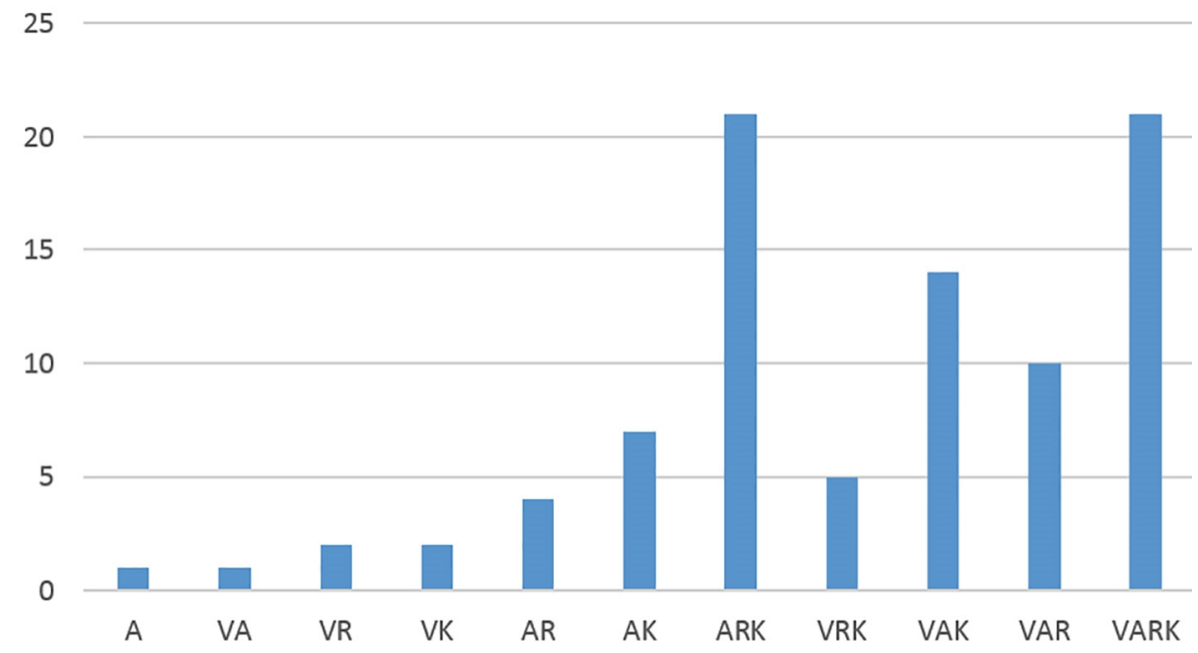

Figure 1. Distribution of students' learning style preferences $\mathrm{V}$ : visual, A: aural, R: reading-writing, $\mathrm{K}$ : kinesthetic 
There was no significant difference between the mean of the final exam scores in students with and without aural learning style preference $(p=0.865)$, reading-writing learning style preference $(p=0.205)$ and kinesthetic learning style preference $(p=0.328)$. In addition, there was no significant difference between final clinical course scores in different learning style preferences separately $(\mathrm{p}>0.05)$. However, there was a significant difference between the mean of final exam scores in students with and without visual learning style preference $(p=0.034)$ so that individuals with visual learning style preference had higher mean scores (Table 1). Furthermore, there was a significant association between students' grades and visual learning style preference $(p=0.019)$, so that $45 \%$ of fourth-year students, $79 \%$ of the fifth-year students, and $65 \%$ of the sixth-year students preferred the visual learning style. Finally, there was no significant relationship between learning style preferences and gender $(p>0.05)$.

Table1. Relationship between learning styles and the mean of student's final exam scores

\begin{tabular}{|l|l|l|l|}
\hline Student's learning styles & Frequency(n) & Scores mean \pm SD & p-value \\
\hline With visual style & 56 & $16.27 \pm 1.14$ & 0.03 \\
\hline Without visual style & 32 & $15.72 \pm 1.16$ & \\
\hline With aural style & 79 & $16.05 \pm 1.14$ & \multirow{2}{*}{0.86} \\
\hline Without aural style & 9 & $16.13 \pm 1.49$ & \\
\cline { 1 - 3 } With reading-writing style & 63 & $16.18 \pm 1.04$ & \multirow{2}{*}{0.2} \\
\cline { 1 - 3 } Without reading-writing style & 25 & $15.77 \pm 1.42$ & \\
\hline With kinesthetic style & 70 & $16 \pm 1.15$ & \\
\hline Without kinesthetic style & 18 & $16.31 \pm 1.25$ & \\
\hline
\end{tabular}

\section{Discussion}

This study was performed on fourth-, fifth-, and sixth-year dental students at Babol University of Medical Sciences. One of the main findings of this study was that individuals with visual learning style preference had better academic status than individuals without visual learning style preference. However, there was no difference between other learning style preferences in the mean of students' final exam scores. In addition, there was no significant difference between final clinical course scores in different learning style preferences. The aim of this study was to determine the relationship between the mean of students' final exam scores, gender, and students' grade levels and learning styles based on the VARK standard questionnaire. Awareness about the learning styles of learners is very important in education systems and helps instructors identify and solve learning problems of learners. Furthermore, it helps learners learn more easily and efficiently (8). In this research the majority of students (98.9\%) preferred to use multiple learning styles. In a study conducted by Alipour et al. (12) on nursing students, $93 \%$ of participants preferred multimodal learning styles. Of those, 19, 51, and 23\% preferred bimodal, tri-modal, and quad-modal styles, respectively.

In a study by Peyman et al. (8) on first-year medical science students in Iran, $41.8 \%$ of students preferred single modal, with $58.2 \%$ and $27 \%$ preferring multimodal and quad-modal learning styles, respectively. Sinha et al. (3) found multimodality to be the preferred learning style among $56 \%$ of clinical students in a Malaysian medical college. In another study by Poonam Kharb et al. (2) of first-year medical students, the majority of the students (61\%) preferred the multimodal learning style. In a study by Prabha (4) of first-year dental students in Tamil Nadu, most of the participants (58\%) preferred a single mode of information presentation. The authors assumed that, since all of the students in Iran have to pass a general university entrance exam (Konkur) to select their university major and have to get a higher score to be accepted in dentistry colleges, those students who have the multimodal learning style and use all of their multiple senses are more likely to reach this academic status. There are only few studies that have evaluated the relationship between dental students' learning styles and their academic status using the VARK inventory. A study conducted by Al-Saud (10) in Saudi Arabia found that more than half of the students (59\%) preferred multiple learning styles. Furthermore, there was a statistically significant association between the GPA (grade point average) of students and their learning style preferences, and a higher mean GPA was found among students with multiple (quad-modal) learning style preferences. A study in India (15) of undergraduate medical students found no statistical association between learning style preference and academic performance based on grades. In addition, two other studies on students in physiology classes found no association between learning styles and course scores $(16,17)$. A study by Alkhasawneh et al. (18) found that students with multimodal learning style performed better in a nursing course. Since there were various learning style preferences and our sample size was small, it was difficult to investigate the relationship between every student's learning style(s) and her/his mean of final exam scores. Therefore, we had to investigate the relationship between students' mean of final exam scores 
and having or not having one of the visual, aural, reading-writing, and kinesthetic learning styles. In this study, students with visual learning style had better mean of final exam scores in comparison with those who did not have this learning style. Since the most common teaching method in Babol University is the use of Power Point slides and educational videos, students with visual learning style had better mean of final exam scores because of the compatibility between the teachers' teaching methods and students' learning styles.

Another important finding in our study was that there was no significant relationship between gender and students' grade level and learning style preferences. Similarly, Javadinia et al. (13), Ahadi et al. (19), and Alkhasawneh et al. (18) found no differences between males' and females' learning styles. In a study by Dobson (17) of students in physiology classes, there were significant differences between learning styles and gender. Choudhary et al. (20) and Almigbal (21) also found a significant relationship between gender and learning style preferences.

This study had some limitations. The most important one was the participants' sampling, which was from a single university with different gender distribution. Also, our sample size was small because some of the sixth-year students graduated from the university and did not return their questionnaires. Therefore, the results cannot be generalized to all the dental students, and a larger study from multiple sites is needed.

\section{Conclusions}

This study demonstrated that the majority of dental students in this institution preferred multimodal learning styles and there was a significant relationship between visual learning style preference and the mean of students' final exam scores. In addition, male and female students were not different in their learning style preferences. Instructors need to understand how to reach out all the students by understanding how to present information in multiple modes. The results of this study can provide useful information for improving the quality of teaching and learning experiences of dental students.

\section{Acknowledgments:}

This paper describes part of the results of research that was performed for the DDS degree in Dental Education. The authors thank the Research Deputy of Babol Medical Sciences University for financial support of this project (Grant no.: 2314). We also thank Sahar Nasiri for her scientific helps.

\section{Conflict of Interest:}

There is no conflict of interest to be declared.

Authors' contributions:

All authors contributed to this project and article equally. All authors read and approved the final manuscript.

\section{References}

1) Samarakoon L, Fernando T, Rodrigo C. Learning styles and approaches to learning among medical undergraduates and postgraduates. BMC Med Educ. 2013;13:42. PMID: 23521845, PMCID: PMC3620557 doi: 10.1186/1472-6920-13-42

2) Kharb P, Samanta PP, Jindal M, Singh V. The learning styles and the preferred teaching-learning strategies of first year medical students. J Clin Diagn Res 2013;7(6):1089-92. PMID: 23905110, PMCID: PMC3708205. doi: 10.7860/JCDR/2013/5809.3090.

3) Sinha NK, Bhardwaj A, Singh S, Abas AL. Learning preferences of clinical students: A study in a Malaysian medical college. Int J Med Public Health 2013;3:60-63.

4) Prabha V. Learning styles among the first year dental students. Int J Health Sci Res. 2013;3(9):22-28.

5) Sarabi-Asiabar A, Jafari M, Sadeghifar J, Tofighi S, Zaboli R, Peyman H, Salimi M, Shams L. The relationship between learning style preferences and gender, educational major and status in first year medical students: a survey study from iran. Iran Red Crescent Med J. 2014;17(1):e18250. PMID: 25763269, PMCID: PMC4341501 doi: 10.5812/ircmj.18250.

6) Tomas L, Ratcliffe M, Woodbury J, Jarman E. Learning style and performance in the introductory programming sequence. ACM SIGCSE Bulletin 2002;34(1):33-37. doi: 10.1145/563517.563352

7) Valizadeh L, Fathizadeh S, Zamanzadeh V. Nursing and midwifery students' learning styles in Tabriz medical university. Iranian Journal of Medical Education 2006; 6(2):136-140.

8) Peyman H, Sadeghifar J, Khajavikhan J, Yasemi M, Rasool M, Yaghoubi YM, Nahal MM, Karim H. Using VARK Approach for Assessing Preferred Learning Styles of First Year Medical Sciences Students: A 
Survey from Iran. J Clin Diagn Res 2014;8(8):1089-92. PMID: 25302208, PMCID: PMC4190729. doi: 10.7860/JCDR/2014/8089.4667.

9) Shenoy N, Shenoy K A, U P R. The perceptual preferences in learning among dental students in clinical subjects. J Clin Diagn Res 2013;7(8):1683-5. PMID: 24086874, PMCID: PMC3782931. doi: 10.7860/JCDR/2013/4940.3219.

10) Al-Saud LM. Learning style preferences of first-year dental students at King Saud University in Riyadh, Saudi Arabia: influence of gender and GPA. J Dent Educ 2013;77(10):1371-8. PMID: 24098042

11) Amini N, Zamani B, Abedini Y. Learning Styles of Medical Students. Iranian J Edu Med Sci 2010; 10(2): 141-7.

12) Jannat Alipour Z, Navvabi N, Jahanshahi M. Evaluation of nursing students' learning styles based on VARK learning pattern in Ramsar School of Nursing and Midwifery. Biannual J of Med Edu, Babol Uni of Med Sci 2013;1(2):37-45.

13) Javadinia SA, Sharifzadeh Gh, Abedini M, Khalesi MM, Erfanian M. Learning styles of medical students in Birjand University of Medical Sciences According to VARK Model. Iranian J Edu Med Sci 2011;11(6):584-9.

14) Fleming N. Vark: A Guide to Learning Styles (online). Available from: http://www.vark-learn.com.

15) Urval RP, Kamath A, Ullal S, Shenoy AK, Shenoy N, Udupa LA. Assessment of learning styles of undergraduate medical students using the VARK questionnaire and the influence of sex and academic performance. Adv Physiol Educ 2014;38:216-20. PMID: 25179610, PMCID: PMC4154266. doi: 10.1152/advan.00024.2014.

16) Dobson JL. A comparison between learning style preferences and sex, status, and course performance. Adv Physiol Educ 2010;34(4):197-204. PMID: 21098387 doi: 10.1152/advan.00078.2010.

17) Dobson JL. Learning style preferences and course performance in an undergraduate physiology class. Adv Physiol Educ 2009;33(4):308-14. PMID: 19948680 doi: 10.1152/advan.00048.2009.

18) Alkhasawneh IM, Mrayyan MT, Docherty C, Alashram S, Yousef HY. Problem-based learning (PBL): assessing students' learning preferences using VARK. Nurse Educ Today 2008;28:572-579. PMID: 17983691

19) Ahadi F, Abedsaidi J, Arshadi F, Ghorbani R. Learning styles of nursing and allied health students in Semnan university of medical sciences. Koomesh J 2010;11(2):141-147.

20) Choudhary R, Dullo P, Tandon RV. Gender differences in learning style preferences of first year medical students. Pak J Physiol 2011;7:42-45.

21) Almigbal TH. Relationship between the learning style preferences of medical students and academic achievement. Saudi Med J 2015;36(3):349-55. PMID: 25737179, PMCID: PMC4381021. doi: 10.15537/smj.2015.3.10320. 